الزبيدي : استخدام( زيت المحركات المستعمل) كمضاف في الخرسانة المعرضة لارجات الحرارة العالية

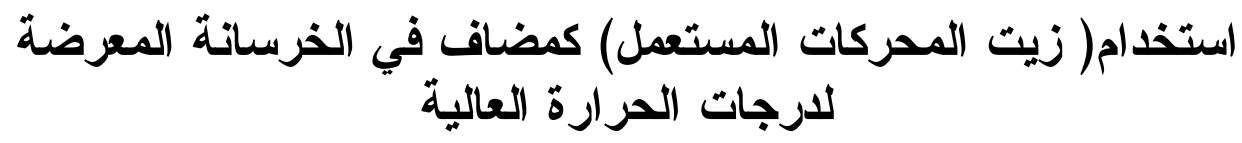

ابتشام حازم حسن الزبيدي

د. عبد الحكيم حامد احمد

مدرس مساعد /قسم الهندسة المدنية

أستاذ في قسم الهندسة المدنية

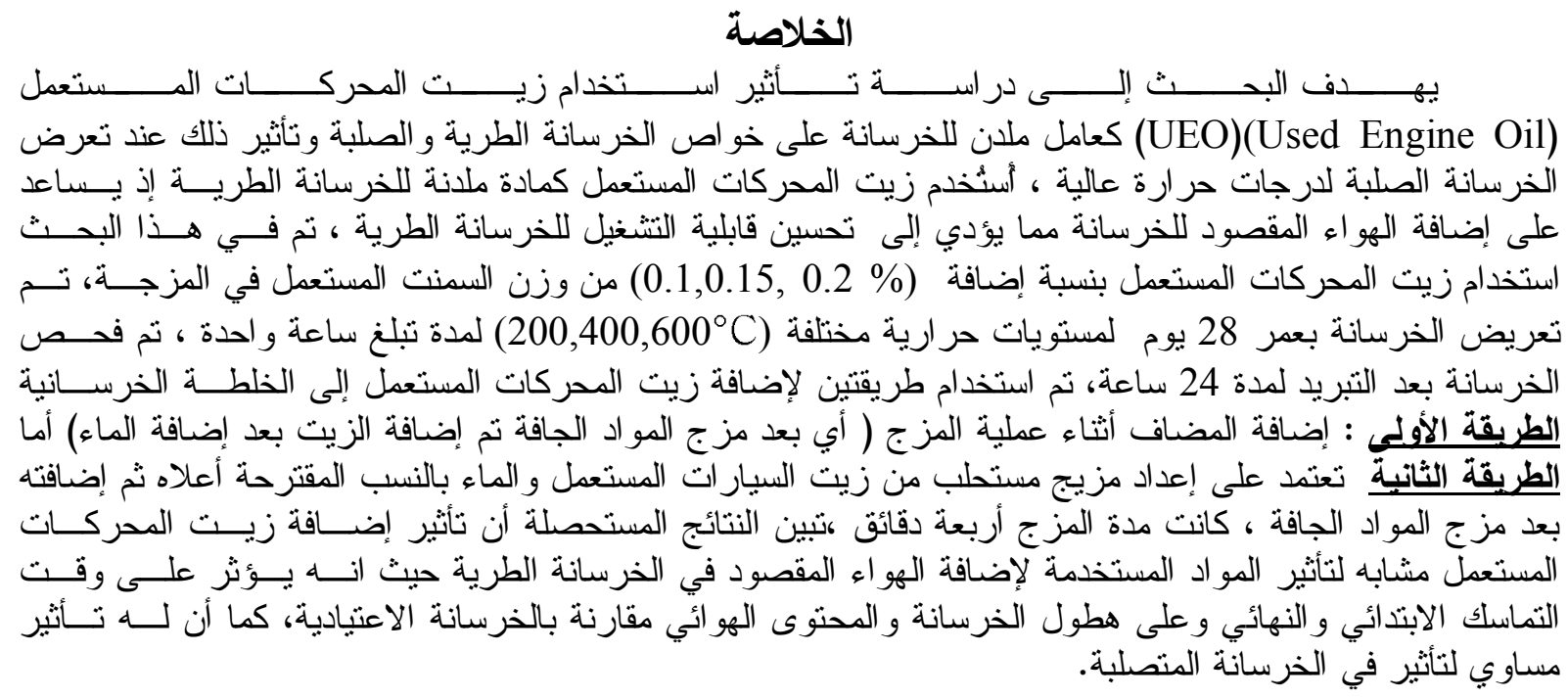

\title{
The Use Of Used Engine Oil As Anadmixture In Concrete With High Temperature
}

\author{
Dr. A.H. Ahmed \\ Prof. /Civil Eng. Dept
}

\section{I.H. AL-Zubady \\ Assist lecturer}

\begin{abstract}
The aim of this research is to study the effect of (Used Engine Oil) (UEO) on the properties of fresh and hardened concrete and its effect on the properties of the hardened concrete under high temperature, the (UEO) used as a plasticizer material, adding an airentrained to the fresh concrete, thus improving workability of the fresh concrete. The (UEO) is used as percentage of cement weight $(0.1,0.15,0.2 \%)$, the 28 day concrete is exposed to different levels of high temperature $\left(200,400,600^{\circ} \mathrm{C}\right)$ for $1.0 \mathrm{hr}$, the concrete samples were tested after $24 \mathrm{hr}$ of cooling, two methods were used to add the (UEO), First Method: adding the (UEO) during the mixing process (mixing the dry materials and water after that the used engine oil was added), The Second Method: An emulsion mixture consisting of oil and water was prepared for the different percentages of additions this emulsion was used after mixing the dry materials, the mixing time was 4 minutes. Results showed that the effect of using the (UEO) is similar to that of air-entraining chemical to fresh concrete, its effect appears on the (initial \& final setting time, slump and air content) and also affects the properties of hardened concrete.
\end{abstract}

Keyword: used engine oil, concrete, high temperature, air-entrained. 


\section{Al-Rafidain Engineering $\quad$ Vol.17 No.6 $\quad$ Dec. 2009}

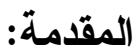

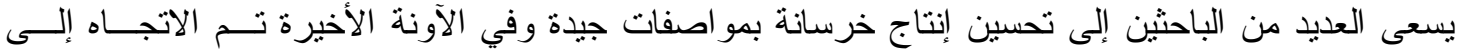

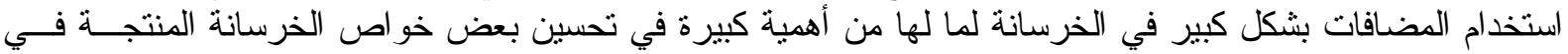

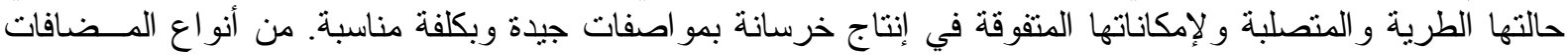

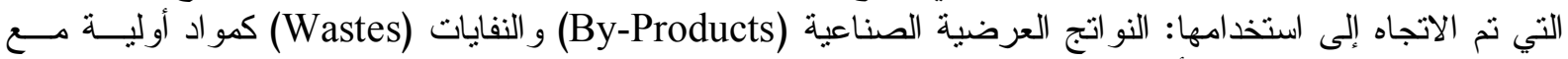

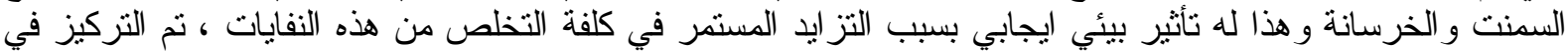

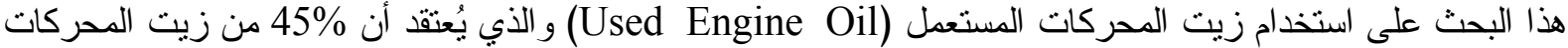

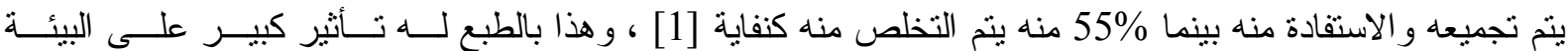

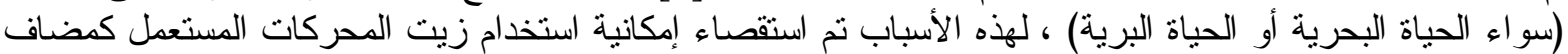
للخرسانة ودر اسة تأثنيره على خو اص اص الخرسانة في حالتها الطرية و المنصلبة.

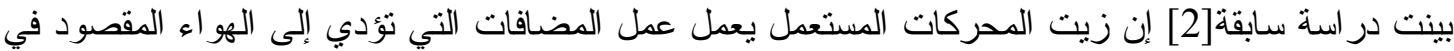

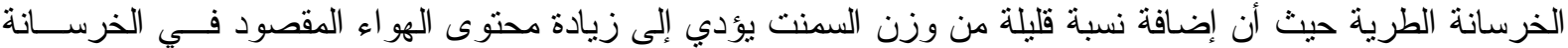

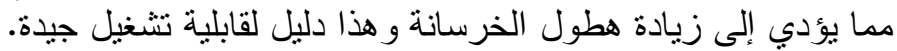

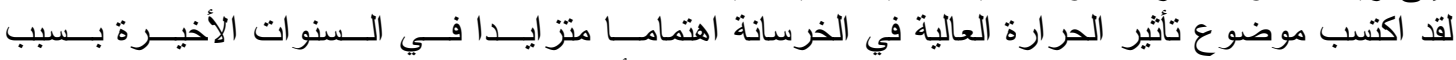

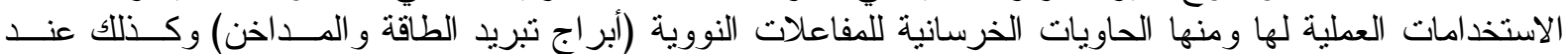

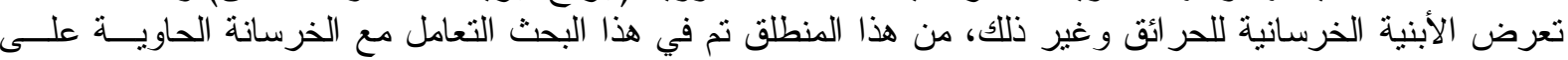

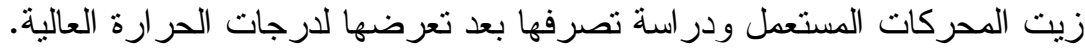

الهذف الرئيسي لهذا البحث هو معرفة تأثير إضافة زيت المحركات المستعمل إلى الخرسانة ودر اسة خو اصها الهـف من البحث:

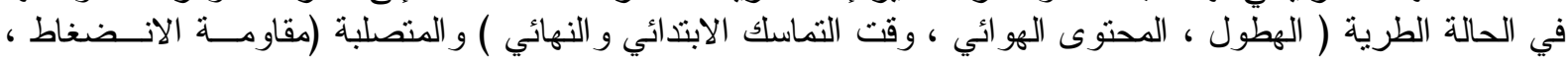

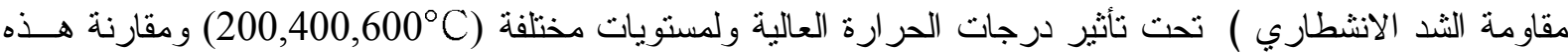

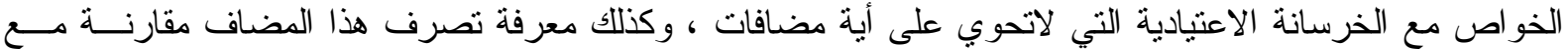

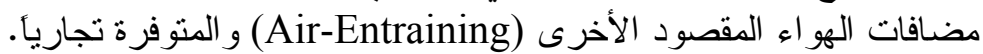

الار اسـات السابقة:

تم تتاول هذا الموضوع من قبل الباحث (Hamad) و آخرون [2] إذ نم در ساتة تأثثر إضافة زيت المحركسـات

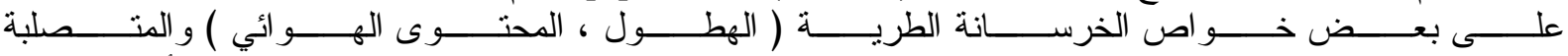

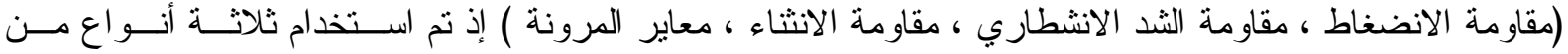

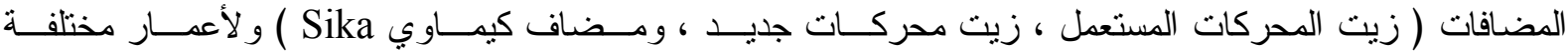

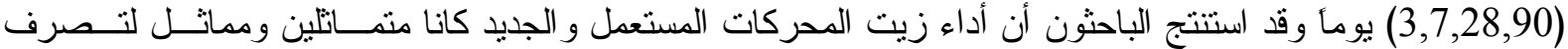

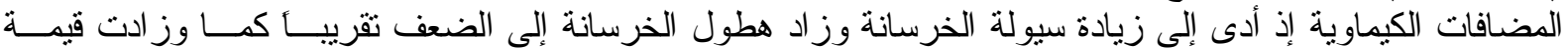

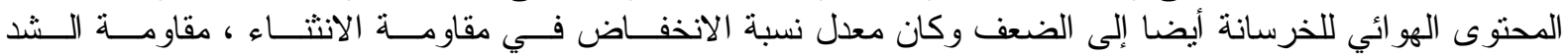

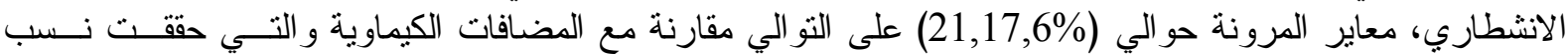

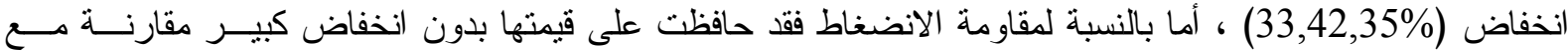
انخفاض 50\% من قيمة مقاومة الانضغاط عند استخدام المضافات الكيماوية الأخرى.

1- المواد المستخدمة: تم استخدام المو اد المتوفرة محلياً وهي السمنت، الماء، الركام الناعم، الركام الخـشن،

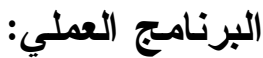
المضاف (زيت المحركات المستعمل).

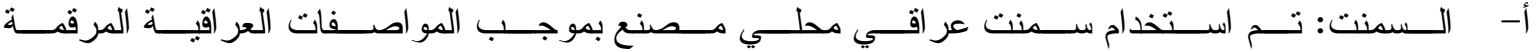

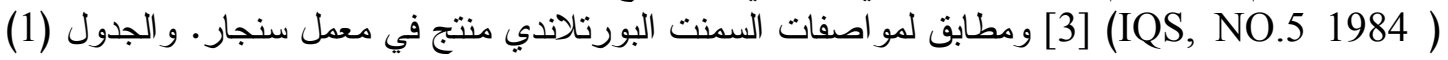

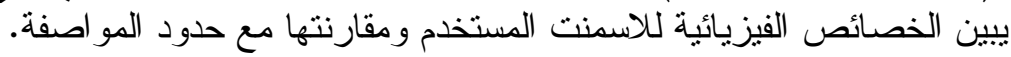

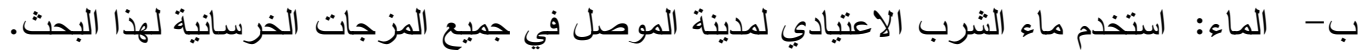

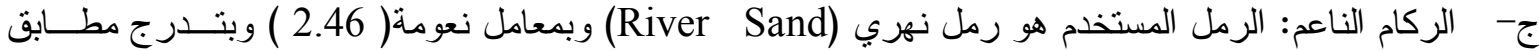

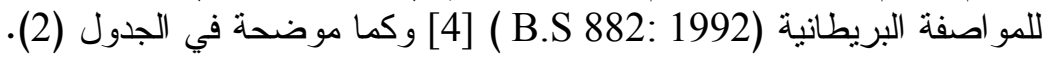


الزبيدي : استخدام( زيت المحركات المستعمل) كمضاف في الخرسانة المعرضة لارجات الحرارة العالية

د- - الركام الخشن: تم استخدام الحصى النهري المحلي المتو افر في إطر اف مدينة الموصل وبمقاس أقصى للركام

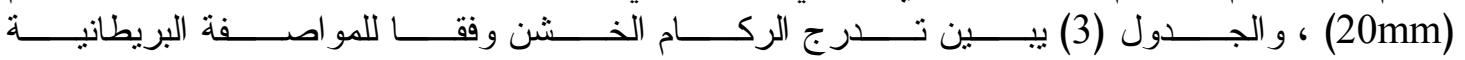
.[4] (B.S 882: 1992)

o- المضاف: تم استخدام زيت المحركات المستعمل كمضاف إلى الخلطة الخرسانية و المنو افر محليا.

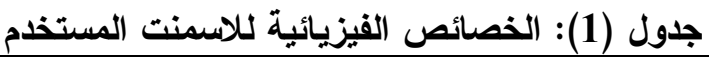

\begin{tabular}{|c|c|c|}
\hline 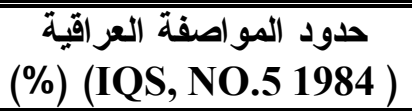 & النتائج & الخصائص \\
\hline لا تزيل عن 10\% & $5 \%$ & النعومة ( نسبة المتبقي على منخل رقم 170 ) \\
\hline & & وقت التماسك \\
\hline لا يقل عن 45 دقيقة & 105 & ابتدائي (دقيقة) \\
\hline لايزيد عن 600 دقيقة & 180 & نهائي (دقيقة) \\
\hline & & مقاومة الآضغاط (MPa) \\
\hline لا تقل عن (16 MPa) & 20 & 3 \\
\hline لا تقل عن (24 MPa) & 28 & أيام \\
\hline & & مقاومة الثد (MPa) \\
\hline لا تقل عن (1.6 MPa) & 1.8 & 3 \\
\hline لا تقل عن (2.4 MPa) & 2.6 & أيام \\
\hline
\end{tabular}

جدول (2): نسب المواد المارة للتحليل المنظلي للرمل المستخدم مع النسب المارة العليا والانيا

للمواصفة البريطانية)( B.S 882: 1992)

\begin{tabular}{|c|c|c|c|}
\hline \% المارة الصغرى & \% المارة لنموذج الرمل & \% القيارة العليا & مقاس المنخل(mm) \\
\hline 89 & 100 & 100 & 4.75 \\
\hline 80 & 88 & 100 & 2.36 \\
\hline 70 & 77 & 100 & 1.18 \\
\hline 55 & 58 & 100 & 0.6 \\
\hline 5 & 24 & 70 & 0.3 \\
\hline 0 & 7 & 15 & 0.15 \\
\hline
\end{tabular}

الجدول (3) يبين تلرج الركام الخشن

\begin{tabular}{|c|c|c|}
\hline \multicolumn{2}{|c|}{ النسبة المئوية المارة للمادة (\%) } & \multirow[b]{2}{*}{ مقاس المنخل(mm) } \\
\hline $\begin{array}{c}\text { حلود المواصفة البريطية } \\
\text { \% ( B.S 882: 1992) }\end{array}$ & الأموذج & \\
\hline 100 & 100 & 37.5 \\
\hline $90-100$ & 95 & 20 \\
\hline $40-80$ & 60 & 14 \\
\hline $30-60$ & 45 & 10 \\
\hline $\mathbf{0 - 1 0}$ & $\mathbf{0}$ & 5 \\
\hline
\end{tabular}




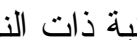

عاد

مت الاعت

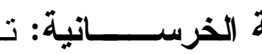

2- 2

الوزنية (0.5 / 4 : 1.5 : 1:5 وبمعدل مقاومة انضغاط (36.7 ) كخلطة مرجعية، تم في هذا البحث تحضير ســبعة

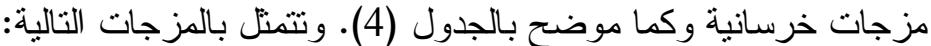

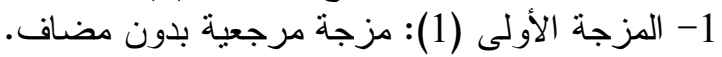

2- المزجة الثانية (2): إضافة المضاف أثثاء عملية المزج ( أي بعد مزج المو اد الجافة نم إضافة زيــت المحركــات المستععل بعد إضافة الماء).

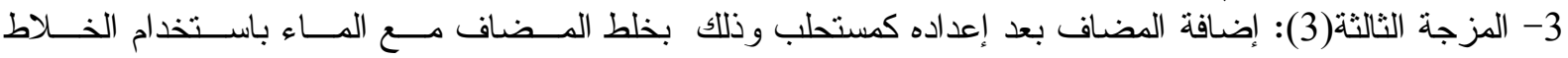

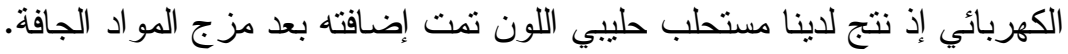
الجدول (4) : نسب المزجات الخرسانية

\begin{tabular}{|c|c|c|c|}
\hline طريقة المزج & (زيت المحركات المضتعمل) & اللمبيج الوزنية & رقم المزجة \\
\hline (1) بدون مضاف & 0.0 & $(1: 1.5: 4 / 0.5)$ & M1 \\
\hline \multirow{3}{*}{ 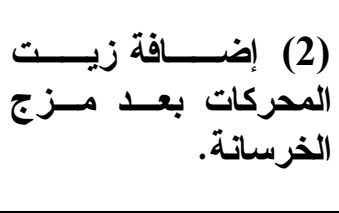 } & 0.10 & $(1: 1.5: 4 / 0.5)$ & M2 \\
\hline & 0.15 & $(1: 1.5: 4 / 0.5)$ & M3 \\
\hline & 0.20 & $(1: 1.5: 4 / 0.5)$ & M4 \\
\hline \multirow{3}{*}{ 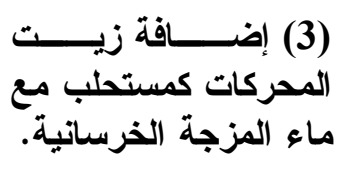 } & 0.10 & $(1: 1.5: 4 / 0.5)$ & M5 \\
\hline & 0.15 & $(1: 1.5: 4 / 0.5)$ & M6 \\
\hline & 0.20 & $(1: 1.5: 4 / 0.5)$ & M7 \\
\hline
\end{tabular}

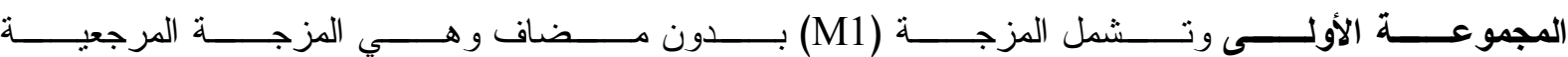
المجموعة الثانية تضم المزجات (M2, M3, M4) كانت نسبة المضاف (2) (0.1, 0.15, 0.2 مسن وزن الـسمنت

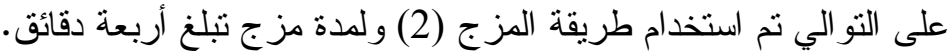

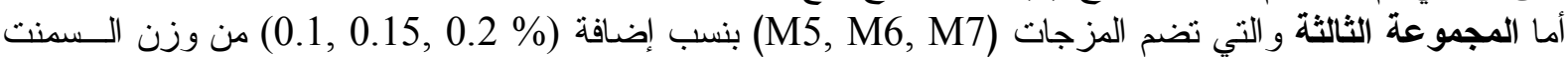

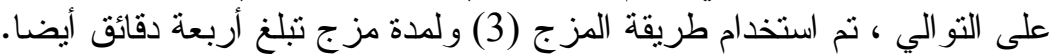

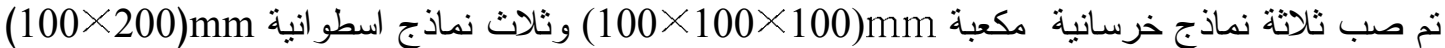

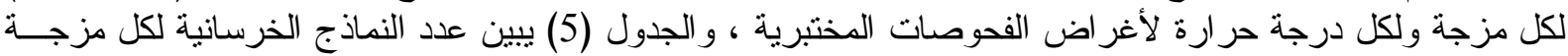
الني أعدت لغرض وض در اسة الخصائص الأساسية اللازمة لهذا البحت البحث.

الجدول (5) يبين عدد النماذج الخرسانية المطلوبة لكل مزجة

\begin{tabular}{|c|c|c|}
\hline عدد النماذج & نوع الفصص & درجة الحرارة Co \\
\hline 3 & مقاومة الانضغاط & \multirow{2}{*}{20} \\
\hline 3 & مقاومة الثد الانشطاري & \\
\hline 3 & مقاومة الانضغاط & \multirow{2}{*}{200} \\
\hline 3 & مقاومة الثد الاششطاري & \\
\hline 3 & مقاومة الآضغاط & \multirow{2}{*}{400} \\
\hline 3 & مقاومة الثد الآشطاري & \\
\hline 3 & مقاومة الانضغاط & \multirow{2}{*}{600} \\
\hline 3 & مقاومة الشد الاشظطاري & \\
\hline
\end{tabular}

ع.مجموع النماذج لكل مزجة خرسانية بلغت 24 نموذج أي لجميع المزجات الخرسانية المشار إليها في جدول (4) بلغت 168 نموذج. 


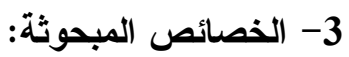

• الخرسانة الطرية: ، نم ايجاد الهطول و المحتوى الهوائي ووقت التماسك الابتدائي و النهائي لجميع المزجـات

الخرسانية.

الخرسانة المتصلبة: ، تم ايجاد مقاومة الانضغاط ومقاومة الثد الانشطاري لجميـع المزجــات الخرسـانية

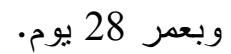

4- تسخين النماذج الخرسانية إلى درجات الحرارة العالية وتبريدها: تم استخدام فرن كهربائي ذو حجــرة و واســـة

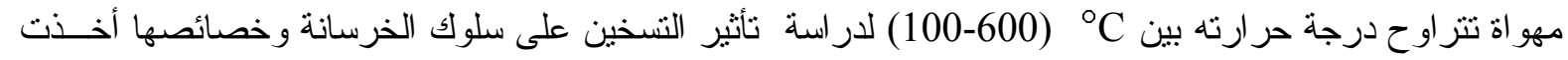

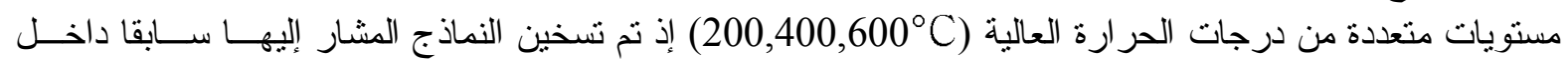

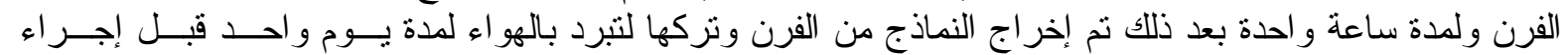
الفحوصات المطلوبة.

النتائج و المناقشتة:

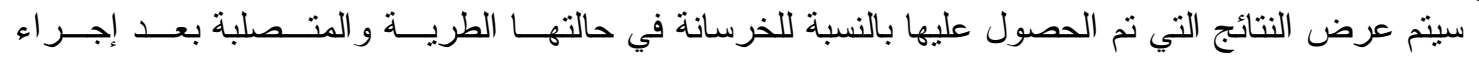

الفحوصات المقررة إضافة إلى مناقشتة النتائج وتحلئيلها.

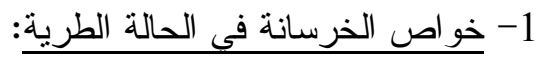

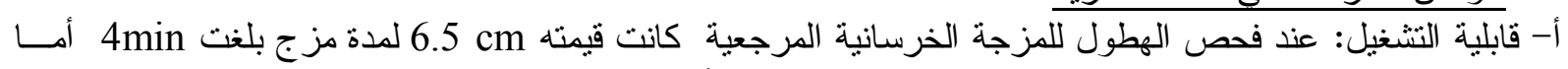

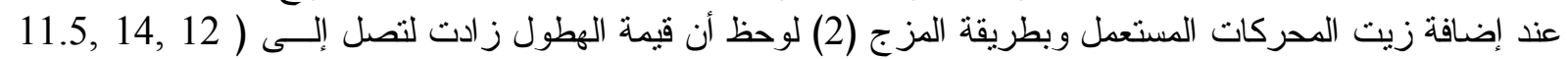

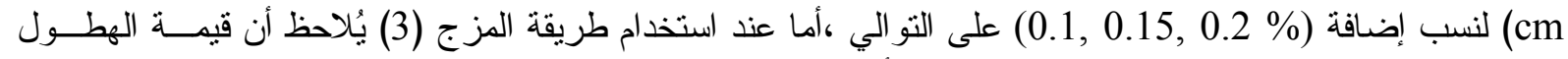

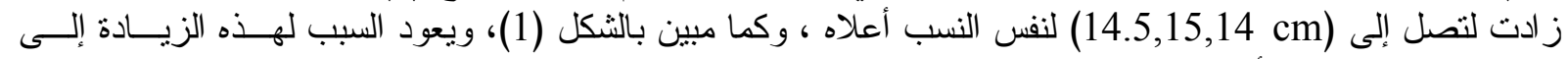
انتتار المضاف بشكل أوسع ومتجانس بين جزيئات الخرسانة.

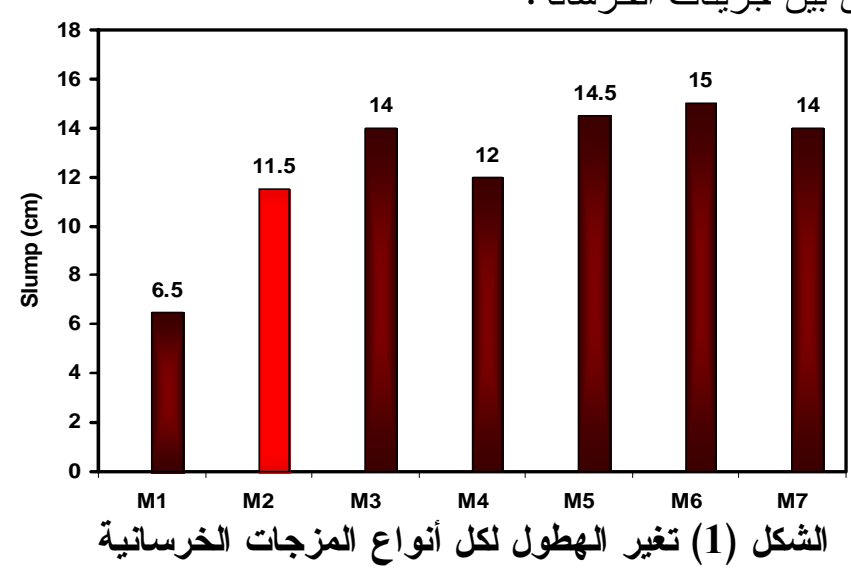

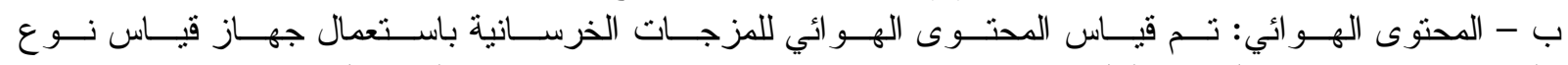
(Maruto Airmeter )

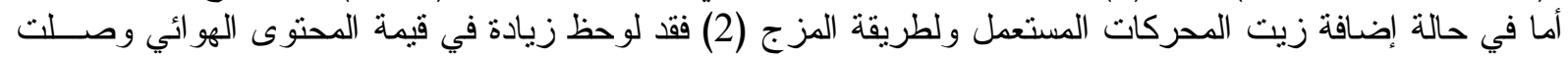

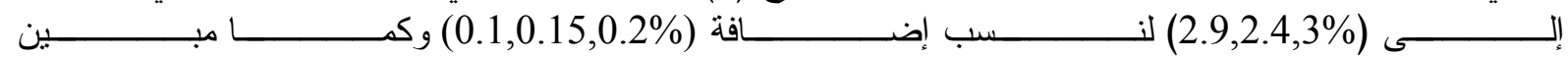
بالثكل (3) ، أما لطريقة المزج (3) فقد بلغت قيمة المحتوى الهو ائي (2 3 (2, 3.2, 2.8).

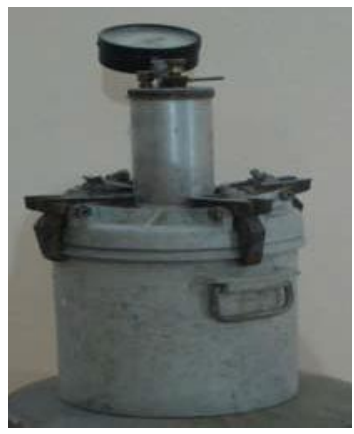

الشكا، (2) حعاز ق قـاس ، المحته ع، العه ائ, 


Al-Rafidain Engineering $\quad$ Vol.17 $\quad$ No.6 $\quad$ Dec. 2009

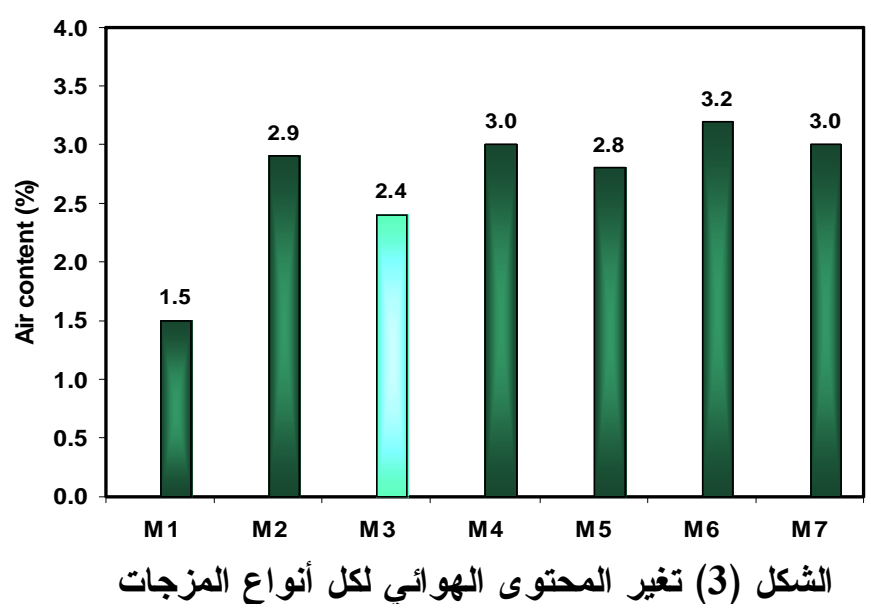

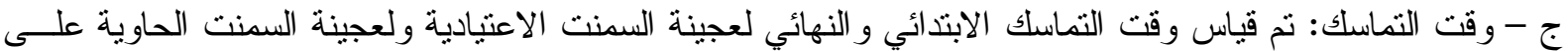

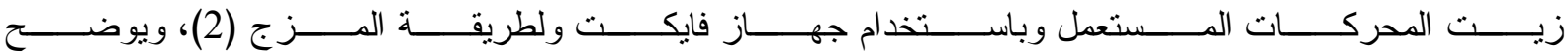
الجدول (6) جميع النتائج و التي تم الحصول عليها للخو اص أعلاه:

الجدول (6) : خواص الخرسانة في الحالة الطرية

\begin{tabular}{|c|c|c|c|c|c|c|}
\hline طريقة المزج & $\begin{array}{c}\text { وقتاسك التهائي } \\
\text { التكائي } \\
\text { (hr:min) }\end{array}$ & $\begin{array}{c}\text { التماسك } 1 \text { التكائي } \\
\text { (hr:min) } \\
\text { (hr:min }\end{array}$ & $\begin{array}{l}\text { المحتوى ائي } \\
\text { \% }\end{array}$ & $\begin{array}{l}\text { الهوطول } \\
\text { (mm) }\end{array}$ & $\begin{array}{c}\text { نسبة } \\
\text { \% }\end{array}$ & رقزجة \\
\hline (1) بذون مضاف. & 3:00 & $1: 45$ & 1.5 & 65 & 0.0 & M1 \\
\hline \multirow{3}{*}{ 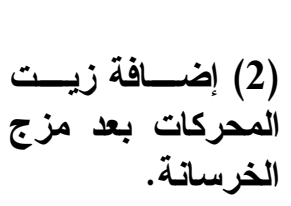 } & $2: 30$ & $1: 40$ & 2.9 & 115 & 0.10 & M2 \\
\hline & $2: 30$ & 2:00 & 2.4 & 140 & 0.15 & M3 \\
\hline & 3:00 & 2:05 & 3.0 & 120 & 0.20 & M4 \\
\hline \multirow{3}{*}{ 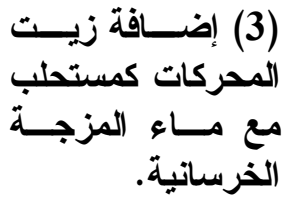 } & $2: 43$ & 1:50 & 2.8 & 145 & 0.10 & M5 \\
\hline & $2: 20$ & $1: 40$ & 3.2 & 150 & 0.15 & M6 \\
\hline & $3: 15$ & 2:00 & 3.0 & 140 & 0.20 & M7 \\
\hline
\end{tabular}

يُلاحظ من الجدول أعلاه أن وقت التماسك الابتدائي لعجينة السمنت الاعتيادية ذات القوام القياسي للمزجة المرجعية

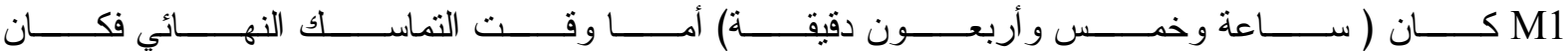
(ثلاث ساعات) وقد تتاقص هذا الوقت إلى (ساعة و أربعون دقيقة) بالنسبة إلى وقت التماسك الابتدائي و(ســاعتين

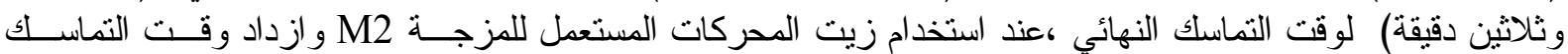
الابتدائي إلى (ساعتين) للمزجة M3 أما بالنسبة لوقت التماسك النهائي فقد تتاقص ليصل إلى ( ساعتين وثناثثن دقيقــة) وقد ازداد وقت التماسك الابتدائي للمزجة M4 إلى اللى (ساعتين وخمس دقائق) .

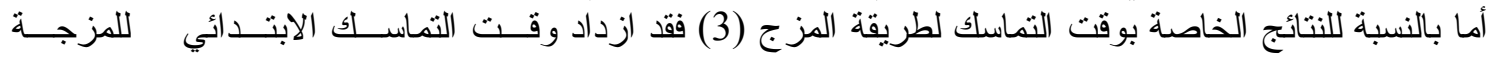

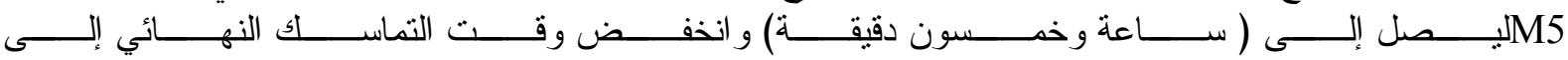

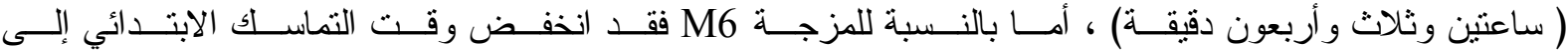

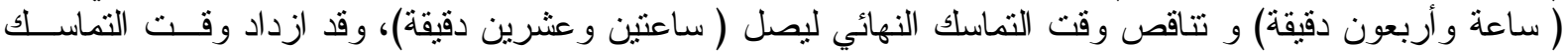

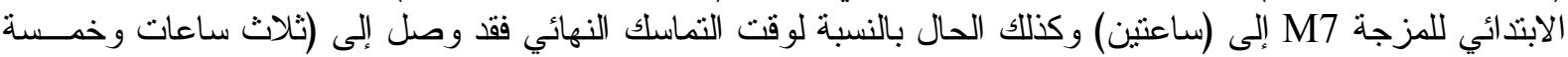


الزبيدي : استخدام( زيت المحركات المستعمل) كمضاف في الخرسانة المعرضة لارجات الحرارة العالية

2- خو اص الخرسانة في الحالة المتصلبة تحت تأثثير درجات الحر ارة العالية:

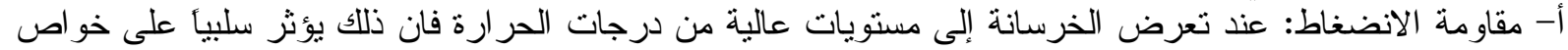

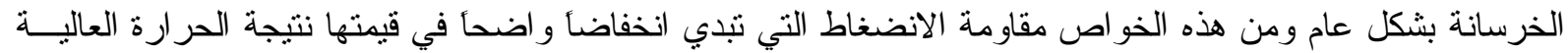

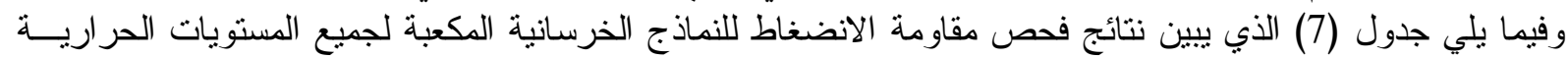
(200,400,600²)

الجدول (7) : مقاومة الاضضغاط للمزجات الخرساتية (طريقة المزج 2) تحت تأثير درجات الحرارة العالية

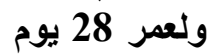

\begin{tabular}{|c|c|c|c|c|}
\hline \multicolumn{4}{|c|}{ مقاومة الأضغاط للمزجات الخرسانية (MPa)" } & \multirow{2}{*}{$\begin{array}{c}\text { درجة (الحرارة } \\
\left({ }^{\circ} \mathrm{C}\right)\end{array}$} \\
\hline $\begin{array}{l}\text { M4 } \\
\text { (2) }\end{array}$ & $\begin{array}{r}\text { M3 } \\
\text { (2) } \\
\end{array}$ & $\begin{array}{c}\text { M2 } \\
\text { (2) }\end{array}$ & $\begin{array}{l}\text { M1 } \\
\text { (1) }\end{array}$ & \\
\hline 33.40 & 31.40 & 32.80 & 36.70 & 20 \\
\hline 28.60 & 29.30 & 24.40 & 35.90 & 200 \\
\hline 31.30 & 30.80 & 28.80 & 35.10 & 400 \\
\hline 22.70 & 25.90 & 22.90 & 28.70 & 600 \\
\hline
\end{tabular}

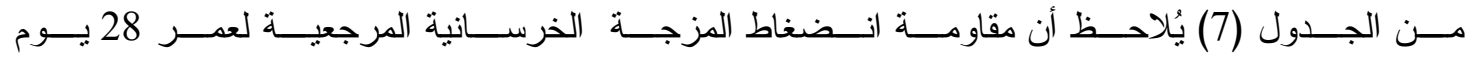

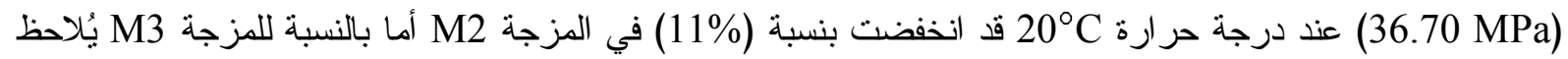
أن مقاومة الانضغاط انخفضت بمقدار (15\%) وللمزجة M4 كان الانخفاض بمقدار (9\%)،كما يُّاحظ أن قيمة مقاومة

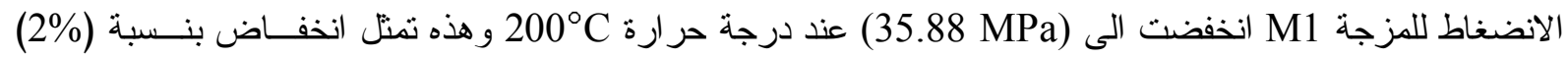

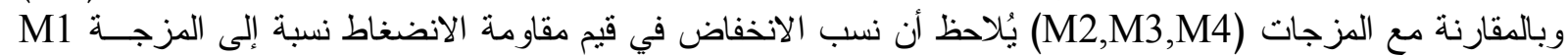

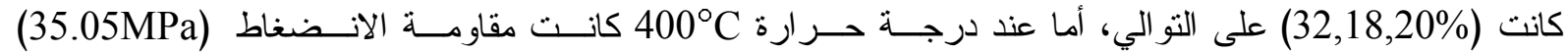
للمزجة M1 , إذ كانت نسب الانخفاض في قيم مقاومة الانضغاط للمزجات ألمات أعلاه (18) (18,12,11\%) على التو الي ، أما عند

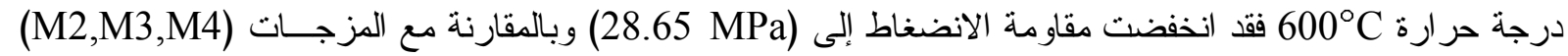

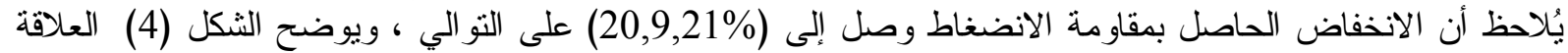

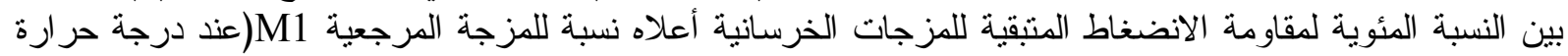
النقات $20^{\circ} \mathrm{C}$ النتائج أن إضافة(

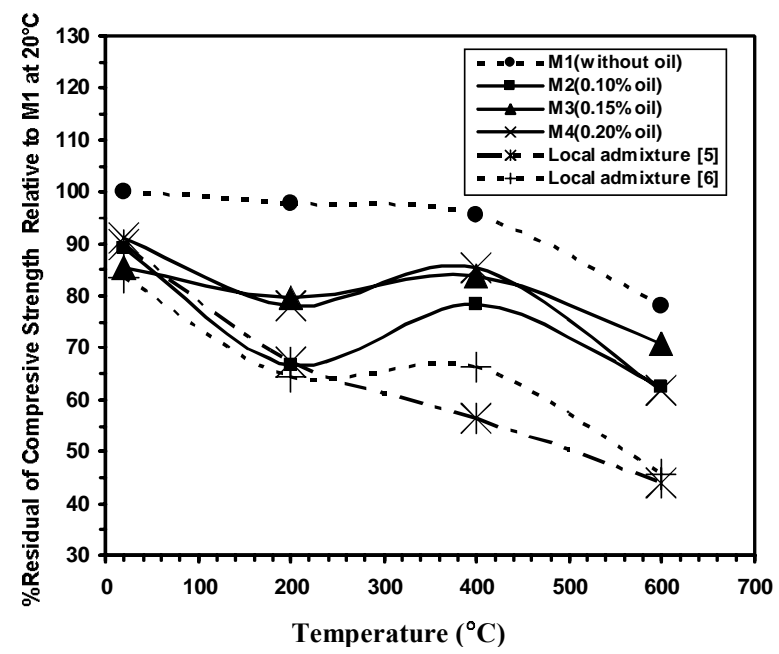

الثكل (4) العلاقة بين النسبة المئوية لمقاومة الاضضغاط المتبقية

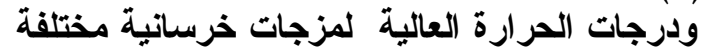




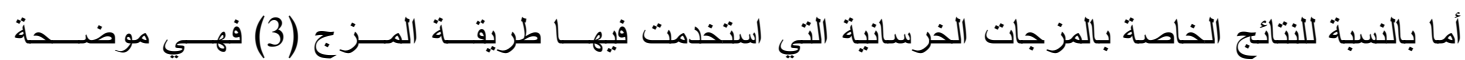

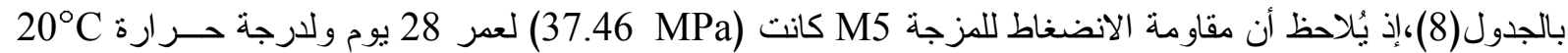

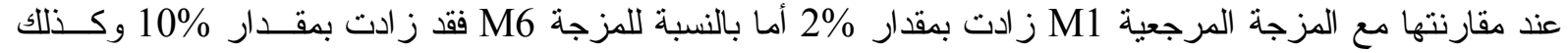
الحال بالنسبة للمزجة M7 حيث أن مقاومة الانضغاط ازدادت بمقدار

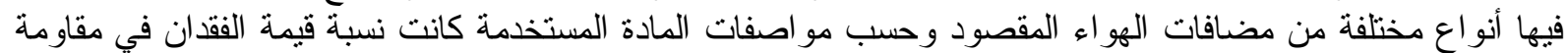

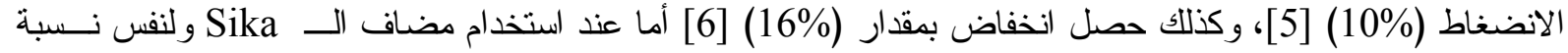

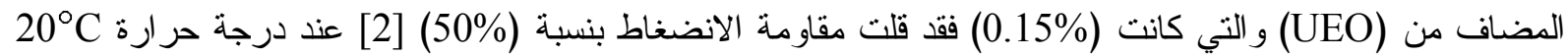

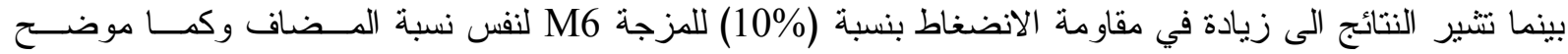

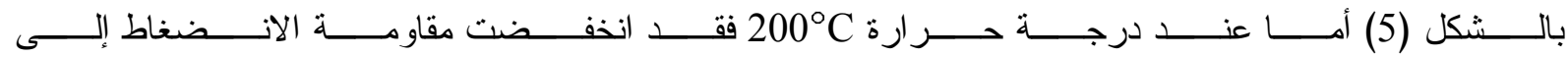
(32.81, 32.47, 34.64 MPa)

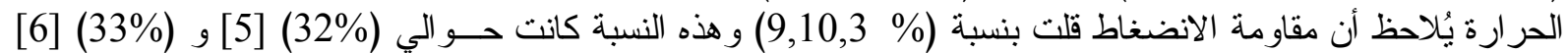
أما عند درجة حر ارة 400

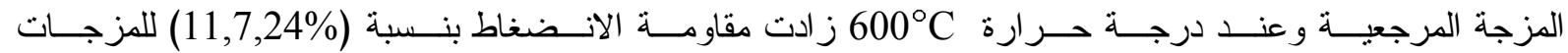

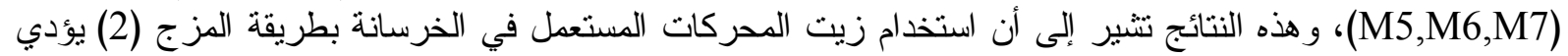

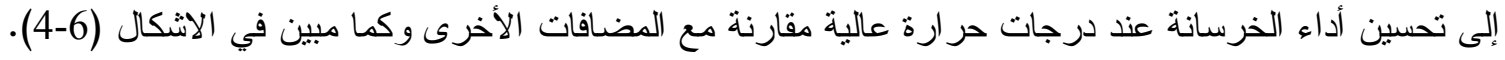

الجدول (8) : مقاومة الاضغاط للمزجات الخرسانية (طريقة المزج 3) تحت تأثير درجات الحرارة العالية

ولعمر 28 يوم

\begin{tabular}{|c|c|c|c|c|}
\hline \multicolumn{4}{|c|}{ مقاومة الانضغاط للمزجات الخرسانية (MPa) م" } & \multirow{2}{*}{ درجة الحرارة } \\
\hline $\begin{array}{r}\text { M7 } \\
\text { (3) } \\
\end{array}$ & $\begin{array}{r}\text { M6 } \\
(3) \\
\end{array}$ & $\begin{array}{l}\text { M5 } \\
(3) \\
\end{array}$ & $\begin{array}{l}\text { M1 } \\
\text { (1) }\end{array}$ & \\
\hline 39.50 & 40.50 & 37.50 & 36.70 & 20 \\
\hline 34.60 & 32.50 & 32.80 & 35.90 & 200 \\
\hline 37.10 & 36.80 & 37.00 & 35.10 & 400 \\
\hline 35.60 & 30.70 & 31.70 & 28.70 & 600 \\
\hline
\end{tabular}

"مقاومة الانضغاط تمثل معدل ثلاثة نماذج

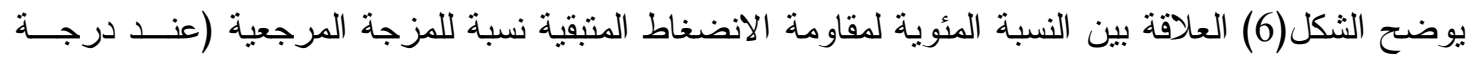

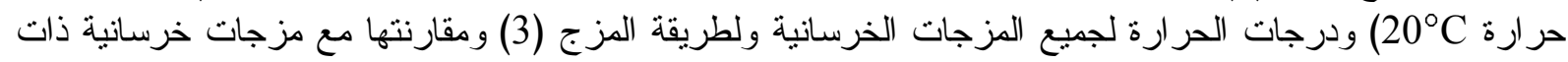

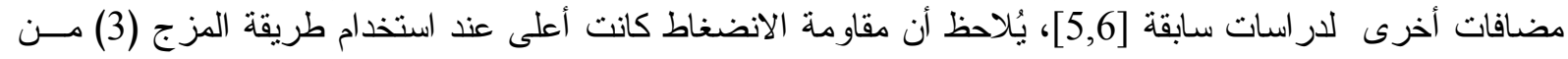

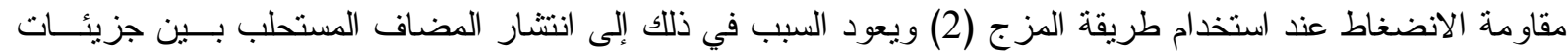

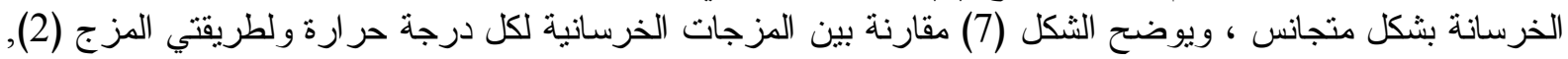

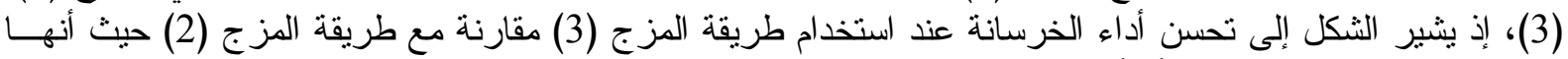
تعطي مقاومة انضغاط مقاربة أو أعلى من الخرسانة الاعنيادية الخدية عند درجات الحر ارة العالية.

ب- مقاومة الثد الانشطاري : تعد مقاومة الثند بصورة عامة من الخواص المهمة في الخرسانة إذ تبلغ مقاومــة الــشد

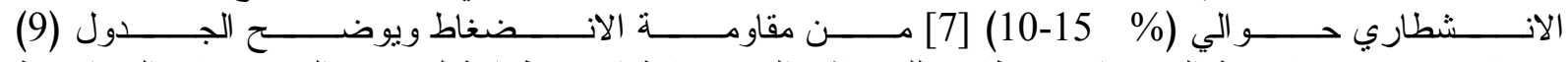

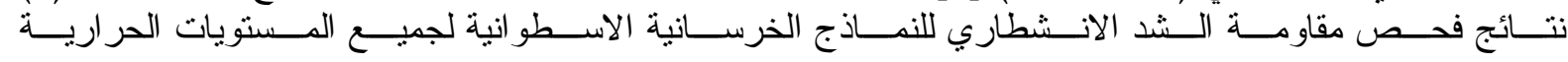
. $(200,400,600)^{\circ} \mathrm{C}$

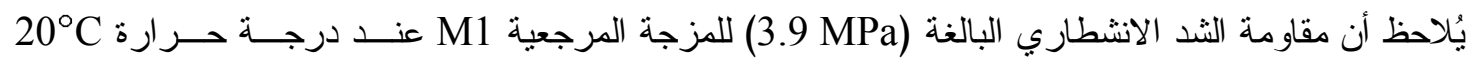

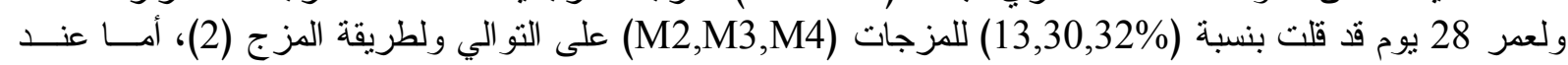

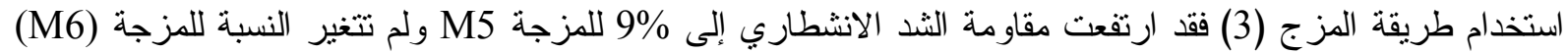

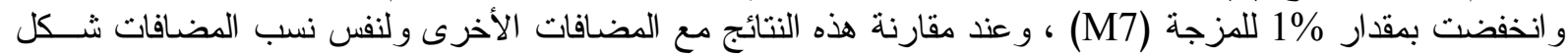

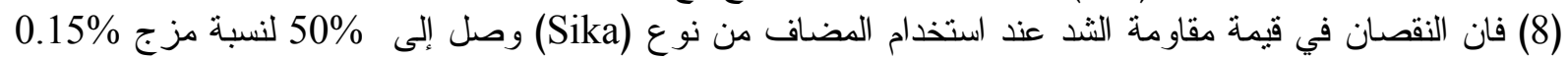
[2]، وبنسبة 10\% عند استخدام أنواع أخرى من مضافات الهو اء المقصود وبالنسب المقترحة بموجب مو اصفات كل 


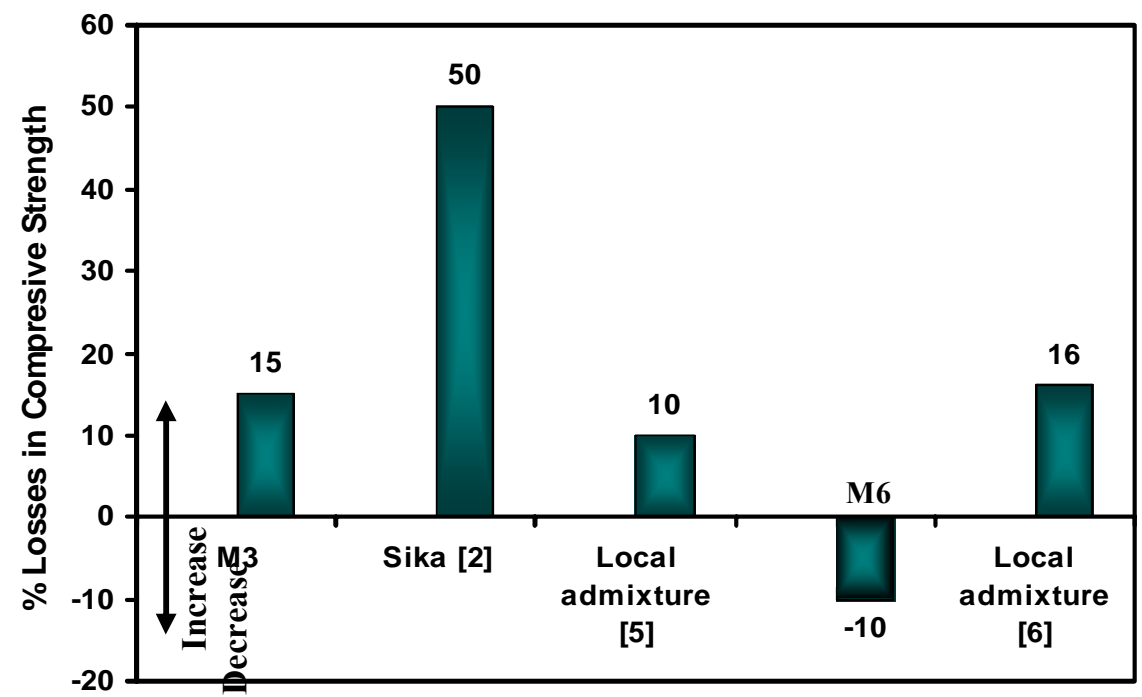

الشكل (5) العلاقة بين قيمة الفقان لمقاومة الانضغاط لمزجات

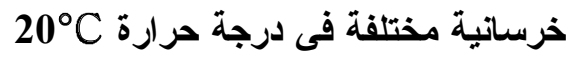

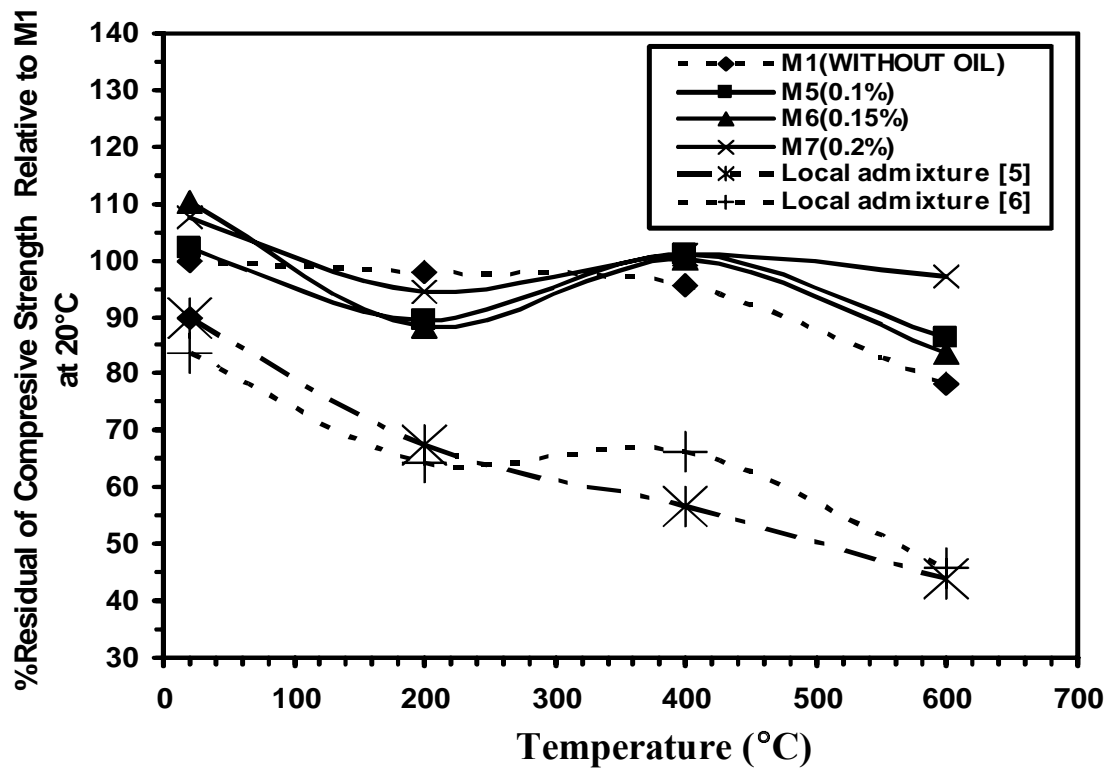

الثكل (6) العلاقة بين النسبة المئوية لمقاومة الإضغاط

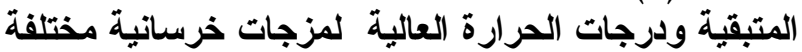

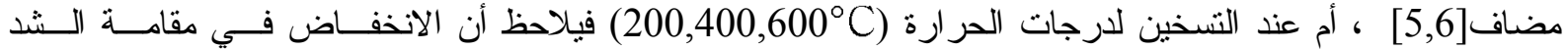
الانتطاري للمزجات الخرسانية مع إضافة زيت المحركات المستعمل لطريقة المزج (3) (مستحلب) يتحسـسن أداءهـــا

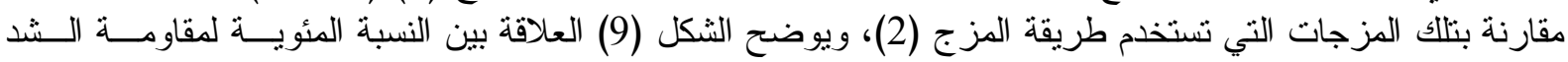

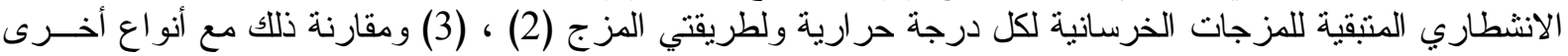




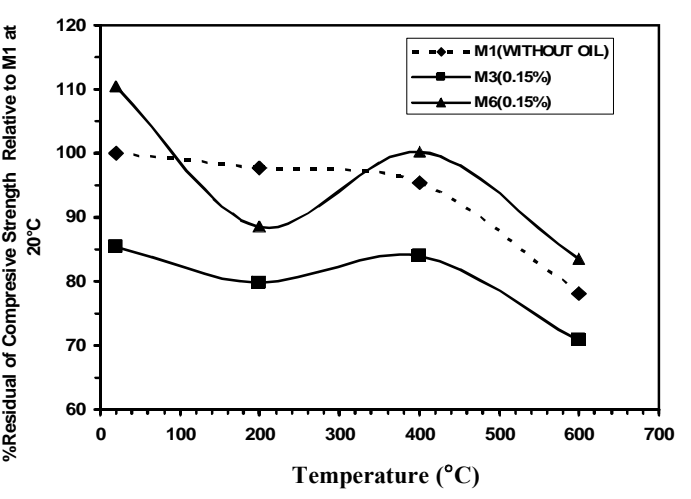

(b)

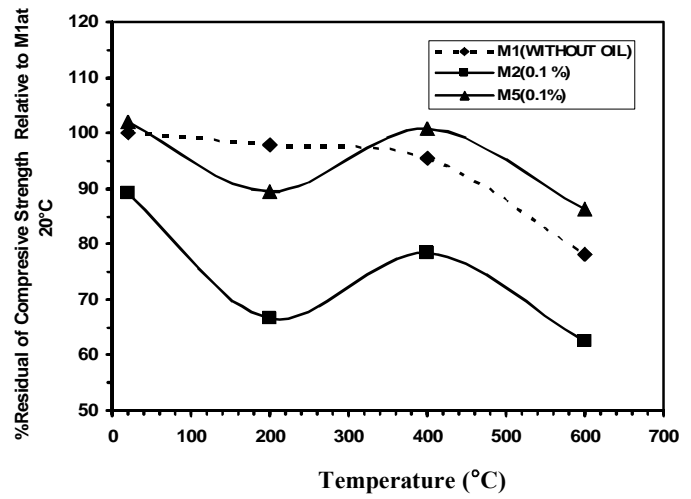

(a)

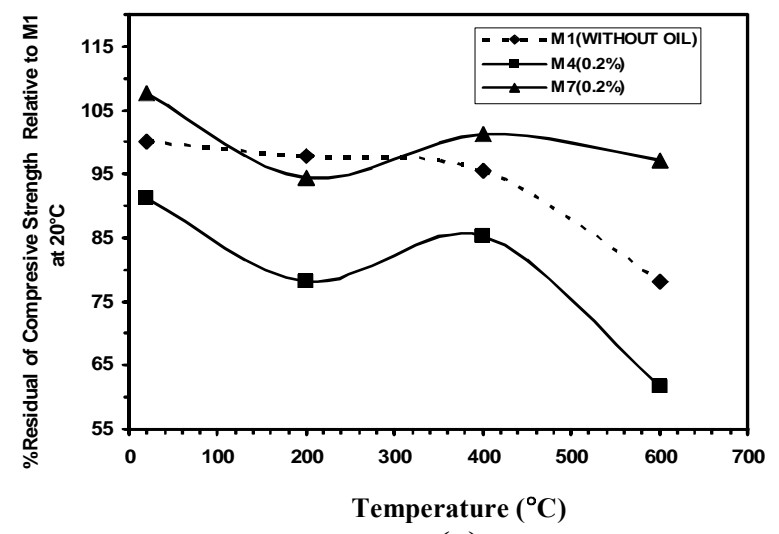

(c)

الثكل (7) مقارنة بين النسبة المئوية لمقاومة الانضغاط المتبقية

للمزجات الخرسانية لكل درجة حرارة ولطريقتى المزج (2), (3).

الجدول (9): مقاومة الثد الاشطاري للمزجات الخرسانية تحت تأثير درجات الحرارة العالية ولعمر 28 يوم المزباتئ

\begin{tabular}{|c|c|c|c|c|c|c|c|}
\hline \multicolumn{7}{|c|}{ مقاومة الشد الاتشطاري للمزجات الخرسانية (MPa) } & \multirow{2}{*}{$\begin{array}{c}\text { درجة (الحرارة } \\
\left({ }^{\circ} \mathrm{C}\right.\end{array}$} \\
\hline $\begin{array}{l}\text { M7 } \\
\text { (3) } \\
\end{array}$ & $\begin{array}{r}\text { M6 } \\
\text { (3) } \\
\end{array}$ & $\begin{array}{r}\text { M5 } \\
\text { (3) } \\
\end{array}$ & $\begin{array}{l}\text { M4 } \\
\text { (2) } \\
\end{array}$ & $\begin{array}{r}\text { M3 } \\
\text { (2) } \\
\end{array}$ & $\begin{array}{l}\text { M2 } \\
\text { (2) } \\
\end{array}$ & $\begin{array}{r}\text { M1 } \\
\text { (1) } \\
\end{array}$ & \\
\hline 3.90 & 3.90 & 4.30 & 2.70 & 2.70 & 3.40 & 3.90 & 20 \\
\hline 2.30 & 2.40 & 2.40 & 1.90 & 1.60 & 2.20 & 2.60 & 200 \\
\hline 2.80 & 2.80 & 2.30 & 1.50 & 1.30 & 2.00 & 2.20 & 400 \\
\hline 1.50 & 2.00 & 1.60 & 0.90 & 0.70 & 1.00 & 1.40 & 600 \\
\hline
\end{tabular}

"مقاومة الثد تمثل معدل ثلاثة نماذج 


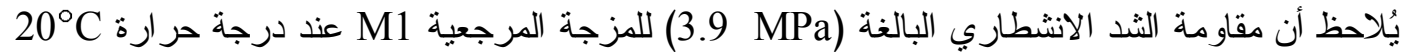

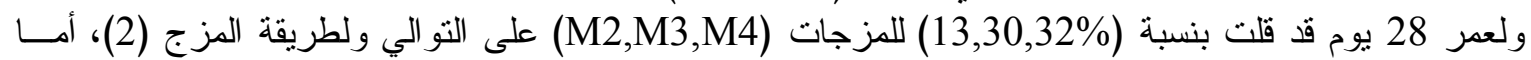

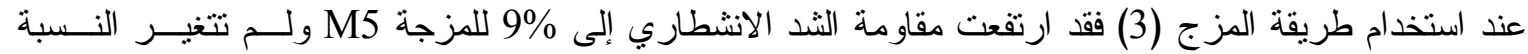

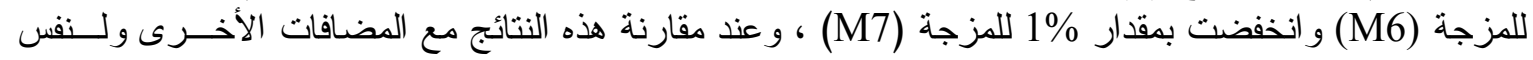

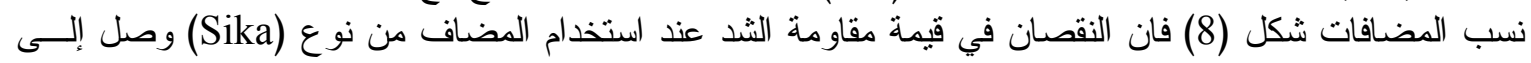

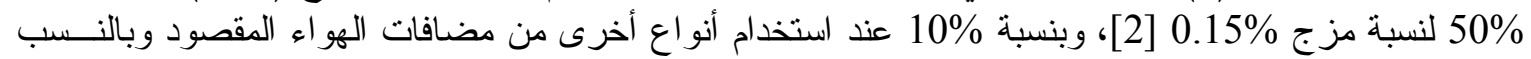

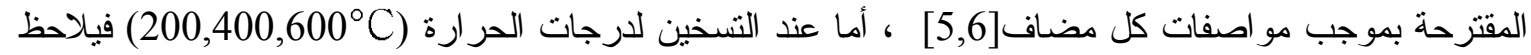

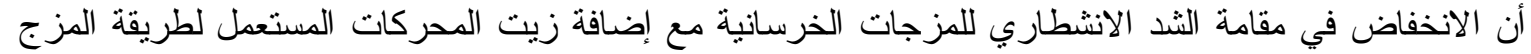

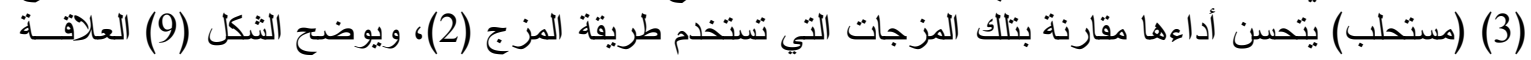

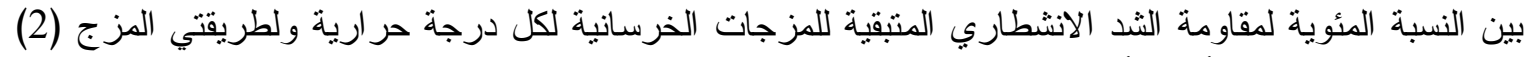

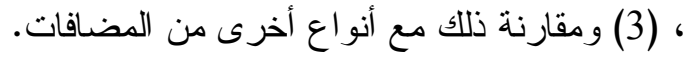

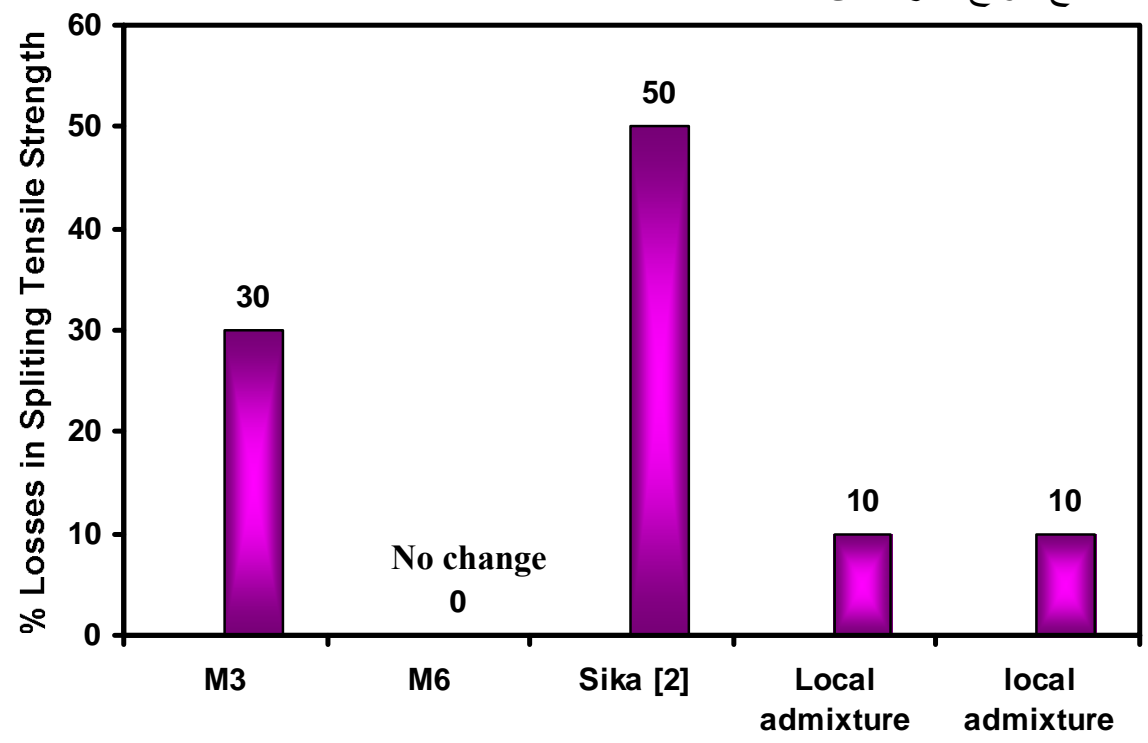

[5]

[6]

الثكل (8) العلاقة بين قيمة الفقدان لمقاومة الثد الاشثطاري

لمزجات خرسانية مختلفة في درجة حرارة لمانه

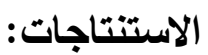

تم التوصل إلى الاستتناجات التالية على ضوء النتائج التي تم الحصول عليها من خلال هذه الدراسة وكما

أ-بلي:- طريقة المزج (2):

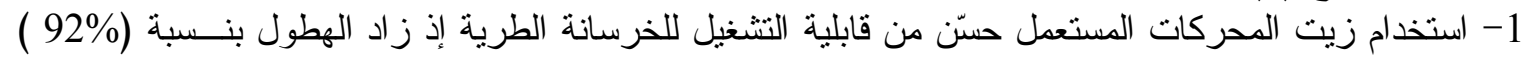

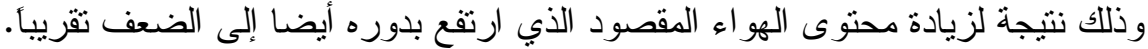

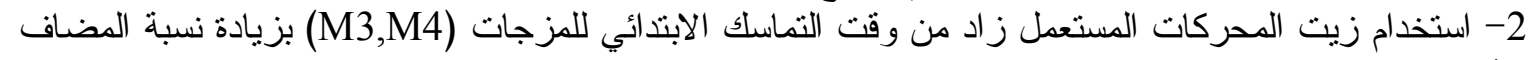

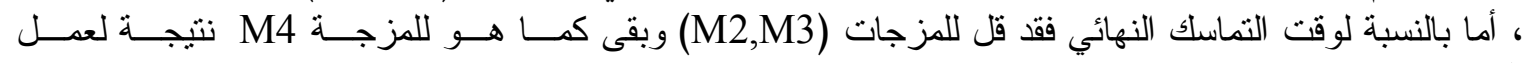
المضاف. 3- ثشتير النتائج إلى أن استخدام نسبة مضاف بمقدار 0.15\% يُحسن من قابلية الخرسانة علـى تحمـل درجــات

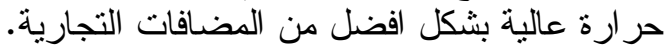

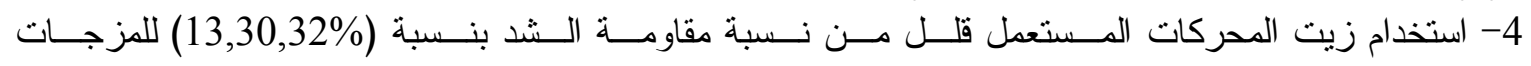
على التو الي عند درجة حر ارة 20C و هذا النقصان يزداد قليلا مع ارتفاع درجـات الحــر ارة ولكافة المزجات. 


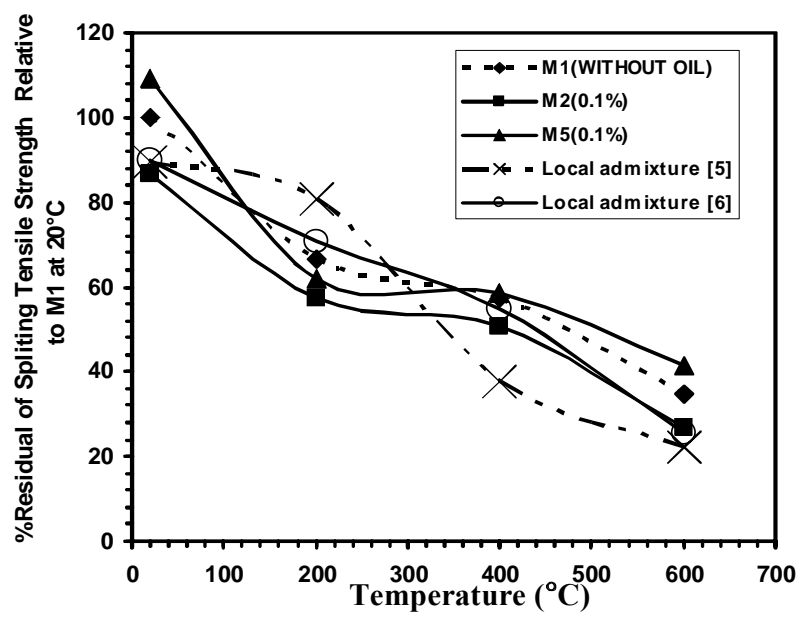

(a)

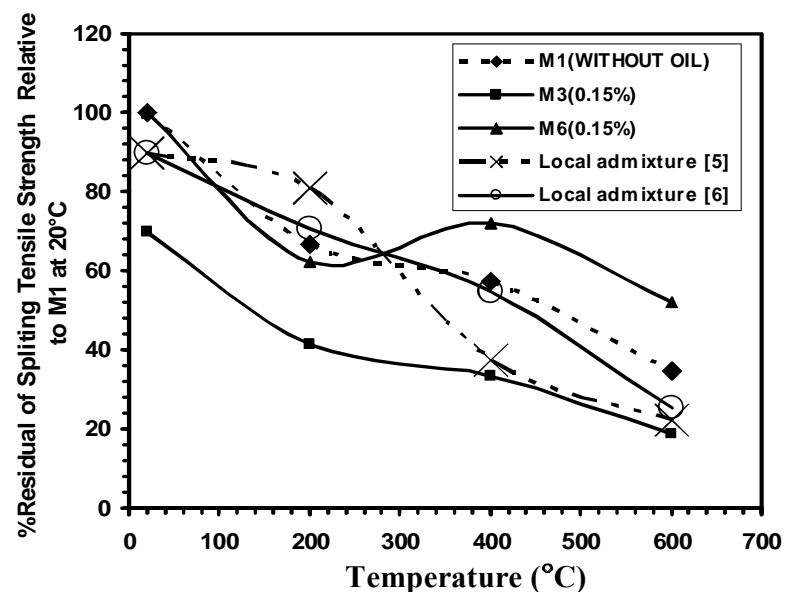

(b)

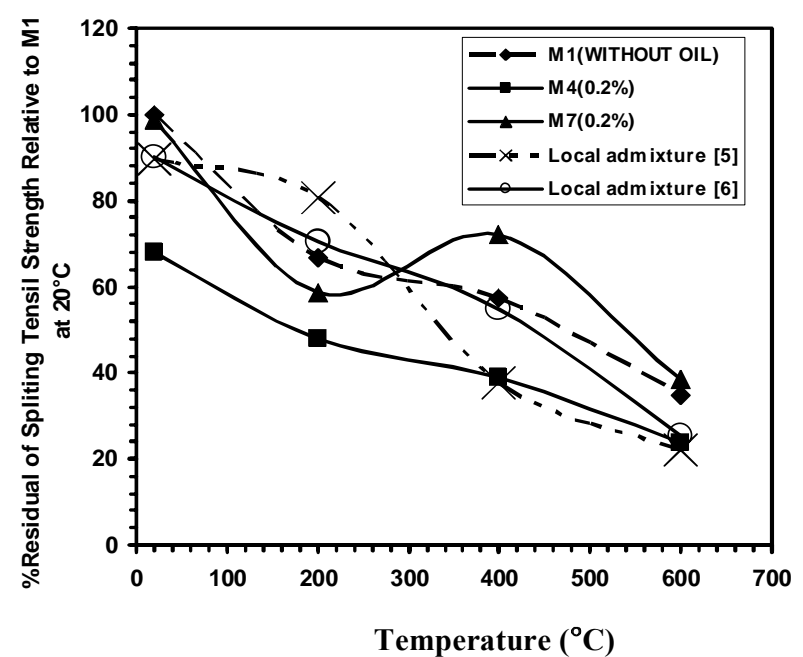

(c)

الشكل (9) مقارنة بين النسبة المئوية لمقاومة الثد الانشطاري المتبقية للمزجات

الخرسانية لكل درجة حرارة ولطريقتي المزج (2), (3). 


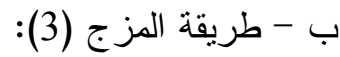
1- استخدام زيت المحركات المستعمل (المستحلب) حسّن من قابلية التشغيل للخرسانة الطرية بنسبة 123\% و هذه

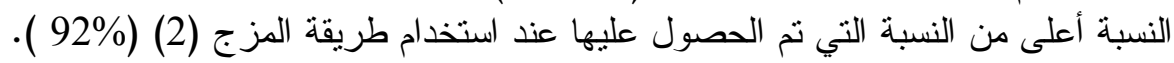
2- استخدام زيت المحركات المستعمل زاد من قيمة المحتوى الهو ائي للخرسانة الطرية بــنفس القيمــة الــسابقة

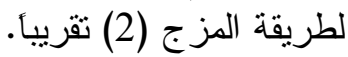
3- ز اد وقت التماسك الابندائي للمزجات (2) (M5,M7) وكان الوقت مقارب لطريقة المزج (2) ، آما وقت التماسك

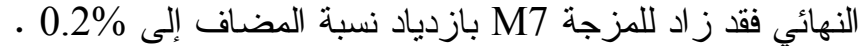
4- ز ادت نسب مقاومة الانضغاط بالمقارنة مع طريقة المزج (2) فقاند كانت نسبة الزيادة مقارنة بالمزجة المرجعية

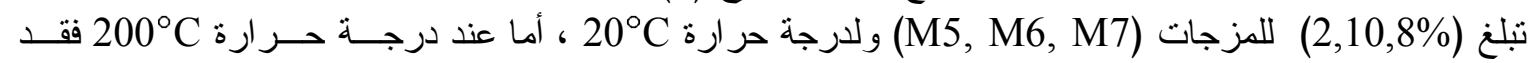

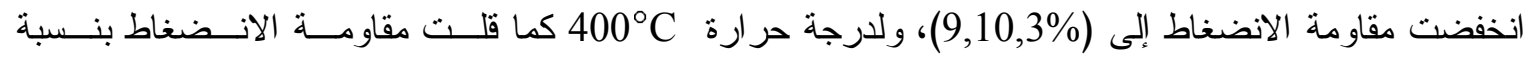

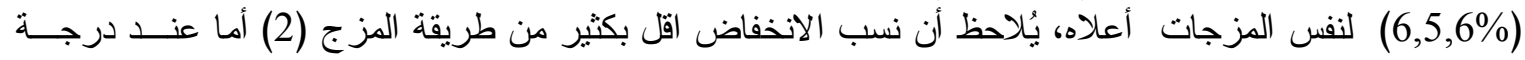

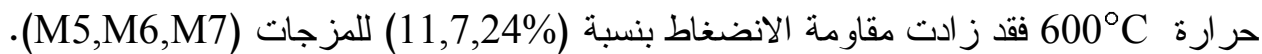
5- استخدام طريقة المزج (3) (إضافة المضاف كمستحلب ) أدى إلى تحسن أداء مقاومة الثند الانشطاري مقارنة

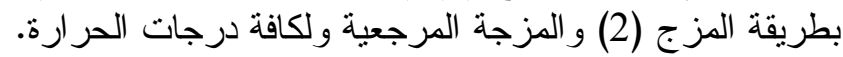

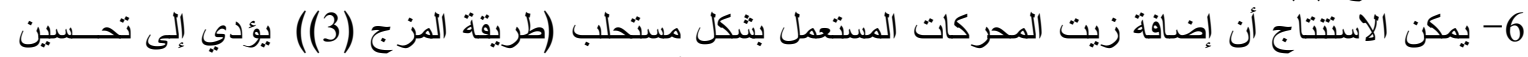

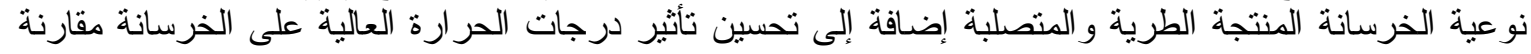

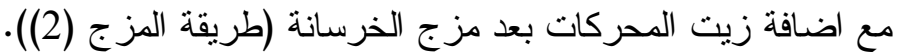

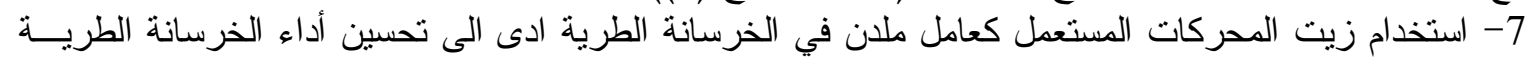

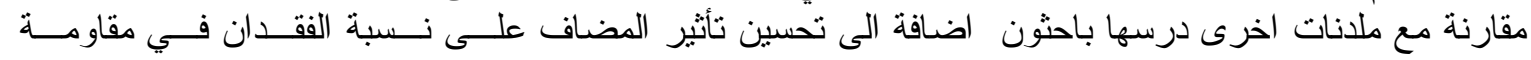

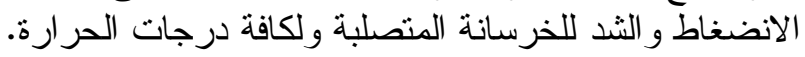

1. EL-Fadel, M. „Khoury, R."Strategies for vehicle waste-oil management :a case study." Resources conservation and recycling. Elsevier, Fuel and Energy Abstracts, Vol.43, Issue 4, July, 2002, P.296.

2. Hamad, B.S. , Rteil, A.A., EL-Fadel, M. "Effect of Used Engine Oil on Properties of Fresh and Hardened Concrete" Construction and Building Materials (Elsevier) ,Vol.17, Issue 5, July , 2003, PP. 311-318.

$$
\text { 3. المو اصفات القياسية (رقم 5)، (1984) " خصائص السمنت البورتلاندي الاعتيادي " ، الجهاز }
$$

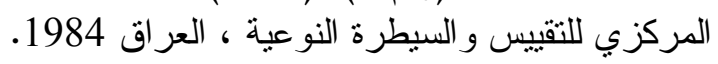

4. BS. 882-1992, "Aggregate From Natural Source for Concrete" , British Standard Institution, 1992.

5. AL-Hayali, O.M., "Comparative Study of Some Properties of Concrete Containing Admixtures Under Effect of High Temperatures", M.Sc. Thesis , University of Mosul , 2006, PP. 57-70.

6. AL-Shahwany, R.B., "Effect of Elevated Temperature on Some Properties of AirEntrained Steel-Fiber Reinforced Concrete", M.Sc. Thesis , University of Mosul, 2007, PP. 47-54.

7. Somayaji, S., "Civil Engineering Materials", Englewood Cliffs, New Jersey, 1995, P.351.

$$
\text { تم اجراء البحث في كلية الهنسسة - جامعة الموصل }
$$

